\title{
High Pressure Measurements and Molecular Modeling of the Water Content of Acid Gas Containing Mixtures
}

\author{
Wael A. Fouad, Matt Yarrison, Kyoo Y. Song, Kenneth R. Cox, and Walter G. Chapman \\ Department of Chemical and Biomolecular Engineering, Rice University, Texas 77005, United States
}

\begin{abstract}
Water content of three carbon dioxide containing natural gas mixtures in equilibrium with an aqueous phase was measured using a dynamic saturation method. Measurements were performed up to high temperatures $\left(477.6 \mathrm{~K}=400{ }^{\circ} \mathrm{F}\right)$ and pressures $(103.4 \mathrm{MPa}=15,000 \mathrm{psia})$. The perturbed chain form of the statistical associating fluid theory (PC-SAFT) was applied to predict water content of pure carbon dioxide $\left(\mathrm{CO}_{2}\right)$, hydrogen sulfide $\left(\mathrm{H}_{2} \mathrm{~S}\right)$, nitrous oxide $\left(\mathrm{N}_{2} \mathrm{O}\right)$, nitrogen $\left(\mathrm{N}_{2}\right)$ and argon (Ar) systems. The theory application was also extended to model water content of acid gas mixtures containing methane $\left(\mathrm{CH}_{4}\right)$. To model accurately the liquid-liquid equilibrium (LLE) at sub-critical conditions, cross association between $\mathrm{CO}_{2}, \mathrm{H}_{2} \mathrm{~S}$ and water was included. The agreement between the model predictions and experimental data measured in this work was found to be good up to high temperatures and pressures.
\end{abstract}

Keywords: PC-SAFT, water content, acid gas, natural gas

* Corresponding Author: Email Address: wgchap@ rice.edu; Tel: 1-713-348-4900, Fax: 1-713-348-5478. 


\section{Introduction}

Natural gas dehydration is an essential process in any natural gas processing plant. The main goal of gas dehydration is removing water to reduce pipeline corrosion and eliminate line blockage caused by hydrate formation. The water dew point should be below the lowest pipeline temperature to prevent free water formation. Also, most product specifications require that no free water be present. As a result, the maximum water content allowed in a sales gas range between 4 to $7 \mathrm{lb} / \mathrm{MMSCF}$. For liquids, the water content is 10 to $20 \mathrm{ppmv}$. Hydrate formation may occur not only in pipelines, but also in cryogenic processes such as the production of liquefied natural gas (LNG) and of $\mathrm{C}_{2}+$ raw materials needed for the polymers industry. Furthermore, enhanced oil recovery (EOR) processes related to the injection of nitrogen or acid gases have gained more attention during the last few years as an effective method of increasing oil and gas production. The process depends on compressing acid gases exiting the amine regenerator overhead or nitrogen exiting the nitrogen rejection unit and transporting them via pipelines to an injection well ${ }^{1,2}$. Consequently, designing both natural gas dehydration and acid gas injection schemes requires a detailed knowledge of wet and sour natural gas mixtures. Experimental data for water content of n-alkanes are widely scattered while that for acid gases is limited. Therefore, rigorous thermodynamic models are needed to accurately predict water content at conditions where experimental data is scattered or does not exist.

\section{Previous experimental efforts in measuring water content of acid gases}

Experimental efforts in measuring water solubility in vapor carbon dioxide phase started back in 1939 by Wiebe and Gaddy $^{3-5}$. Latter, Gillespie and Wilson ${ }^{6}$ as well as Song and Kobayashi ${ }^{7}$ extended the range of existing data to higher pressures where liquid carbon dioxide phase is formed below the pure $\mathrm{CO}_{2}$ critical point. The later also provided extensive data at $\mathrm{CO}_{2}$ 
supercritical conditions. In general, reasonable agreement can be observed among various sets of data above hydrate formation temperatures and up to intermediate pressure regions. Water content for $\mathrm{CO}_{2}+\mathrm{H}_{2} \mathrm{~S}$ mixtures was also measured at several conditions by Clark. ${ }^{8}$ Furthermore, Song and Kobayashi ${ }^{9}$ examined the effect of adding $\mathrm{CO}_{2}$ on water content of methane and ethane supercritical gases. The present work will present new experimental data on the water content of $90 \%$ methane $+10 \%$ carbon dioxide, $30 \%$ methane $+70 \%$ carbon dioxide and $5 \%$ ethane $+95 \%$ carbon dioxide.

Experimental data found in the literature concerning $\mathrm{H}_{2} \mathrm{~S}$ systems is scarce. The work by Selleck et al. ${ }^{10}$ and Gillespie et al. ${ }^{11}$ on water content of vapor and liquid $\mathrm{H}_{2} \mathrm{~S}$ is considered to be the most reliable in the literature. A study by Chapoy et al. ${ }^{12}$ on the phase behavior of waterhydrogen sulfide system has provided more data at low temperatures and pressures. Furthermore, Sharma ${ }^{13}$ examined water content of two different $\mathrm{CH}_{4}+\mathrm{H}_{2} \mathrm{~S}$ mixtures at $327.59 \mathrm{~K}\left(130{ }^{\circ} \mathrm{F}\right)$. Consequently, a fundamental equation of state is needed to safely predict water mole fractions in the absence of experimental data.

\section{Previous modeling efforts in predicting water content of acid gases}

Predicting water content in sweet and sour natural gas systems represents a great challenge to researchers as a result of the low water concentration in the hydrocarbon or acid gas phase. Therefore, most of the techniques used traditionally by the gas industry rely on charts and empirical correlations to approximate water mole fraction. At low pressures where the ideal gas approximation is valid, water content of a gas is approximated to be equal to the vapor pressure of pure water divided by the total pressure of the system. This relation assumes that the solubility of gases dissolved in water is minimal. Therefore, the mole fraction of water in the aqueous phase is taken to be unity. The assumption can be reasonable only in the presence of 
hydrocarbons; however, solubility of acid gases in water can be significant even at low pressures. Sharma and Campbell ${ }^{14}$ were the first to propose a method for calculating water content of sour natural gas mixtures. The model requires the fugacity of water at saturation as well as the fugacity of water and the compressibility factor of the gas mixture at system conditions respectively. A chart was provided to estimate the fugacity at the system conditions. However, the chart is valid only for temperatures between 299.82 and $344.26 \mathrm{~K}\left(80-160{ }^{\circ} \mathrm{F}\right)$ and for pressures less than $13.79 \mathrm{MPa}$ (2000 psia). Later, Maddox ${ }^{15,16}$ developed a similar method which relies on reading water content of sweet natural gas from the McKetta-Wehe chart and then correcting for acid gas presence using other respective charts. The chart for $\mathrm{CO}_{2}$ is for temperatures between 299.82 and $344.26 \mathrm{~K}\left(80-160{ }^{\circ} \mathrm{F}\right)$ and the chart for $\mathrm{H}_{2} \mathrm{~S}$ is for 299.82 and 410.93 K (80-280 $\left.{ }^{\circ} \mathrm{F}\right)$. Both charts are for pressures from 0.69-20.68 $\mathrm{MPa}(100-3000 \mathrm{psia})$. In addition, Carroll ${ }^{17}$ suggested using the Bukacek method ${ }^{18}$ instead of the McKetta-Wehe chart ${ }^{19}$ for estimating water content of the sweet gas needed for the Maddox correction method. Wichert and Wichert ${ }^{20}$ proposed a correction for the McKetta-Wehe chart to take into account $\mathrm{H}_{2} \mathrm{~S}$ in the gas. The correction factor is calculated using a chart which is only valid for temperatures between 283.15 and $449.82 \mathrm{~K}\left(50-350{ }^{\circ} \mathrm{F}\right)$ and a pressure range of 1.38-68.95 $\mathrm{MPa}(200-10,000$ psia). Also, the method is not applicable for $\mathrm{H}_{2} \mathrm{~S}$ equivalent mole fractions greater than 55\%. It is unclear how these methods will behave if extrapolated beyond the range. The pressure and temperature limitations of most of these models are great disadvantages.

Carroll developed a more rigorous thermodynamic model (AQUAlibrium) for estimating water content of sweet and sour natural gas ${ }^{17,21,22}$. The model uses the Peng-Robinson (PR) equation of state $^{23}$ to model the non-aqueous phase while modeling the water-rich phase using Saul and Wagner formulation ${ }^{24}$ of the International Association for the Properties of Water and Steam 
(IAPWS) equation of state for pure water. Hydrocarbon and acid gas solubility in the aqueous phase was calculated using Henry's law relations. The model was applied independently by Carroll $^{17,21,22}$ and Yarrison et al. ${ }^{25,26}$ and showed superiority over other empirical correlations and charts found in the literature. Valtz et al. ${ }^{27}$ used three different models to represent $\mathrm{H}_{2} \mathrm{O}-\mathrm{CO}_{2}$ vapor-liquid equilibrium (VLE). The first model employs the PR equation of state combined with the classical van der Waals one mixing rule for modeling the vapor phase and Henry's law treatment for modeling the liquid phase. The second and third model use the PR equation of state combined with Wong-Sandler/Huron-Vidal mixing rule ${ }^{28,29}$ (PR + WS + NRTL) and SAFT-VR equation of state $\mathrm{e}^{30,31}$ respectively. It is worth noting that SAFT-VR required two large binary interaction parameters to fit the experimental VLE data satisfactory. Results showed that the first and third models gave similar accuracies in predicting $\mathrm{CO}_{2}$ mole fraction in the aqueous phase while the second model produced the best predictions in terms of water content of the $\mathrm{CO}_{2}$ vapor phase. Furthermore, Chapoy et al. ${ }^{12}$ used the Valderrama modification of the Patel-Teja (VPT) equation of state ${ }^{32}$ with the non-density dependent mixing rules ${ }^{33}$ (NDD) for describing $\mathrm{H}_{2} \mathrm{O}-\mathrm{H}_{2} \mathrm{~S}$ binary system phase behavior. Again, a relatively high interaction parameter was used to correlate the experimental data in both phases. Tsivintzelis et al. ${ }^{34,35}$ applied the Cubic-PlusAssociation (CPA) equation of state ${ }^{36}$ to model $\mathrm{H}_{2} \mathrm{O}-\mathrm{CO}_{2}$ and $\mathrm{H}_{2} \mathrm{O}-\mathrm{H}_{2} \mathrm{~S}$ binary systems. Best results were achieved when $\mathrm{CO}_{2}$ was modeled as an electron acceptor while $\mathrm{H}_{2} \mathrm{~S}$ was modeled as an electron donor. Cross association energies were obtained from calorimetric ${ }^{37}$ and infrared (IR) spectroscopic $^{38}$ experiments while cross association volumes were fit to experimental data. However, the work still required large positive binary interaction parameters to enhance the correlation performance. 
A new water model based on the perturbed chain form of the statistical associating fluid theory ${ }^{39-}$ 42 (PC-SAFT) was presented in our previous publications ${ }^{43,44}$. Water in the hydrocarbon phase was modeled as a sphere of diameter $3 \AA$ surrounded by a sea of n-alkane chains. Calculations showed that self-association and multipolar interactions can be neglected in this phase due to the extremely low water mole fractions. Therefore, the water dispersion energy $(\varepsilon / k)$ can be fitted to experimental data available in the literature ${ }^{44}$. The pure liquid water phase was modeled using the accurate IAPWS equation of state ${ }^{45}$. An average dispersion energy of $204.7 \mathrm{~K}$ turned out to be sufficient for correlating water content of the hydrocarbon phase. This value is lower than that fitted by Gross and Sadowski ${ }^{42}$ for their two associating sites water model (one electron donor and one electron acceptor, 2B) but is still higher than that used by water models in molecular dynamic simulation ${ }^{46}$. The remaining association parameters for our four associating sites (two electron donors and two electron acceptors, 4C) model were then fitted to saturated liquid densities and vapor pressures of pure water. Application of the new model to predict water content of pure acid, inert and noble gases, namely: carbon dioxide $\left(\mathrm{CO}_{2}\right)$, hydrogen sulfide $\left(\mathrm{H}_{2} \mathrm{~S}\right)$, nitrous oxide $\left(\mathrm{N}_{2} \mathrm{O}\right)$, nitrogen $\left(\mathrm{N}_{2}\right)$ and argon $(\mathrm{Ar})$ as well as acid gas mixtures with methane is presented in this work.

\section{Experimental Measurement}

\section{Experimental Set $U p$}

The solubility of water in high temperature, high pressure hydrocarbon gases is measured using a flow scheme similar to that of Benson ${ }^{47}$ or Rigby and Prausnitz ${ }^{48}$. Figure 1 shows the important components of the experimental apparatus, which consists of a gas cylinder $(\mathrm{S})$, a $1000 \mathrm{~cm}^{3}$ Ruska boost pump (P1), a $500 \mathrm{~cm}^{3}$ Ruska main pump (P2), a 24 foot thermal equilibration coil (EC), the saturation cell (SC), on-off and throttling valves (TV1 and TV2), analysis train and a 
flow meter (F). Both EC and SC are contained in a thermostatically controlled air bath, which is controlled to within $0.3 \mathrm{~K}$ using a $1.8 \mathrm{KW}$ heater coupled to an OMEGA CN9000A PID temperature controller. The controller parameters were determined using the Cohen-Coontz tuning method.

A detailed drawing of the saturation cell is given in Figure 2. The cell has a nominal internal volume of $1,300 \mathrm{~cm}^{3}$, with an internal diameter of approximately $7.5 \mathrm{~cm}$. Gas enters the cell and flows through a glass dispersion frit (PF) which disperses the gas into the liquid water as bubbles of a nominal diameter of $0.01 \mathrm{~mm}$. A stainless steel retaining ring (RR) holds the frit in place at the bottom of the cell. The bubbles travel through the liquid water phase and into the head space of the saturation cell. A stainless steel baffle and an anti-entrainment section (shown in grey) prevent any water spray from leaving the saturation cell. Gas exits the saturation cell through two throttle valves; (TV1) is a standard vee stem valve, while TV2 is a precision needle valve for precise flow control, which reduces the outlet pressure to approximately 1 bar before passing to the analytical train. Three different pressure transducers (PT) monitor cell pressure; pressures below 70 bar use a Heise transducer, pressures from 70 to 700 bar use a Data Instruments transducer, and pressures from 700 to 1400 bar use a Sensometrics transducer. A J-type thermocouple (TC) located in a thermowell (TW, shown by cross hatching) monitors cell temperature. The J-type thermocouple was calibrated by OMEGA engineering against the ice and boiling points of water, and the melting points of tin and zinc, and was checked against a NIST traceable PRT to confirm the accuracy. An Autoclave Engineers rupture disc (RD) mounted in the anti-entrainment section provides over pressure protection. The dashed line indicates the approximate water level in the cell. 
Analytical train A consists of the General Electric (GE)-Panametrics moisture analyzer (PMA), three desiccant charged stainless steel u-tubes (U) and gas flow meter (F). The PMA measures the water content by measuring the resistance across an aluminum oxide sensor; as the water present in the gas stream changes, so does the resistance across the sensor, which is converted by the PMA into a mole fraction and a mass of water per volume reading. The unit is calibrated by GE using NIST traceable standards, and is recalibrated by GE yearly. Both PMA and the desiccant charged tubes are used at temperatures below $333 \mathrm{~K}$ but temperature limitations of the PMA prevent its use above this temperature. All tubing between the throttle valve (TV1) and analytical train is maintained $10-20 \mathrm{~K}$ above air bath temperature using electrical heating tape to prevent condensation. The expansion pressure inside the detector was maintained constant during a run, and generally varied between 20 and 25 psia.

A Sartorius CP-5000 series scale, with an accuracy of $0.01 \mathrm{mg}$ and a maximum capacity of $300 \mathrm{~g}$ is used to weigh the u-tubes. The scale has an internal calibration and temperature correction features. The calibration is checked periodically against a set of standard grade Ohaus weights. More details on the experimental procedure followed in this work can be found in Yarrison ${ }^{25}$.

\section{Materials}

The gas mixtures were prepared by Aeriform Gas Company, and have an uncertainty in the composition of 0.05 to 0.01 mole percent. Standard laboratory grade deionized, UV sterilized water with a maximum conductance of 0.25 micro siemens $(\mu \mathbf{S})$ is used without further distillation. The anhydrous ACS grade magnesium perchlorate used is from VWR.

\section{Experimental Accuracy and Precision}


The experimental accuracy should be better than 5\% (mole) of water content in the gaseous phase, temperatures should be within $0.5^{\circ} \mathrm{C}$ of set point and pressures should be within $0.01 \%$ of full scale for the high temperature apparatus.

\section{Thermodynamic Modeling}

For a water-gas binary system, the phase equilibrium can be expressed as:

$$
y_{\mathrm{H}_{2} \mathrm{O}} \varphi_{\mathrm{H}_{2} \mathrm{O}}^{\text {sat }} p=\left(1-x_{A G}\right) f_{\mathrm{H}_{2} \mathrm{O}}^{(T, p), p u r e}
$$

Where $y_{\mathrm{H}_{2} \mathrm{O}}$ is the mole fraction of water in the gas rich phase, $\varphi_{\mathrm{H}_{2} \mathrm{O}}^{\text {sat }}$ is the fugacity coefficient of water in the gas rich phase evaluated using PC-SAFT, $p$ is the total pressure, $x_{A G}$ is the gas mole fraction in the water rich phase, and $f_{\mathrm{H}_{2} \mathrm{O}}^{(T, p), p u r e}$ is the fugacity of pure liquid water evaluated at temperature $T$ and pressure $p$. Using the fact that the aqueous phase is predominantly water, the activity coefficient of water is assumed to be unity.

Equating the fugacity of the gas component between the vapor and the aqueous phase gives:

$$
y_{A G} \varphi_{A G}^{s a t} p=x_{A G} H_{A G, H_{2} O}(T, p)
$$

Where $\varphi_{A G}^{\text {sat }}$ is the fugacity coefficient of the gas in the vapor phase evaluated using PC-SAFT. $H_{A G, H_{2} O}$ is the Henry's law constant of the gas in the liquid water phase at temperature $T$ and system pressure $p, y_{A G}$ and $x_{A G}$ are the mole fractions of the gas in the vapor and liquid phases, respectively. $H_{A G, H_{2} O}(T, p)$ is the Henry's law constant for the gas in water at temperature $T$ and pressure $p$. Pressure and temperature dependent Henry's constant for acid/ inert gases considered in this work are calculated using the Krichevsky-Kasarnovsky equation ${ }^{49}$

$$
\ln H_{A G, H_{2} O}(T, p)=\ln H^{A G, 0}+\frac{V_{A G, H_{2} O}^{\infty}}{R T}\left(p-p_{H_{2} O}^{s a t}\right)
$$


where $H^{A G, 0}$ is the Henry's law constant for the gaseous species in water at temperature $T$ and water saturation pressure, and $V_{A G, H_{2} O}^{\infty}$ is the partial molar volume of the gaseous species in water at infinite dilution. $H^{A G, 0}$ for $\mathrm{CO}_{2}, \mathrm{H}_{2} \mathrm{~S}, \mathrm{~N}_{2}$ and $\mathrm{Ar}$ is calculated using a method developed by Harvey ${ }^{50}$ while that for $\mathrm{N}_{2} \mathrm{O}$ using the correlation by Versteeg and van $S$ waalj ${ }^{51} \cdot V_{A G, H_{2} O}^{\infty}$ for $\mathrm{CO}_{2}$, $\mathrm{N}_{2} \mathrm{O}, \mathrm{N}_{2}$ and $\mathrm{Ar}$ is calculated using the corresponding states method of Lyckman et al. ${ }^{52}$ and for $\mathrm{H}_{2} \mathrm{~S}$ using an improved Lyckman type model developed by Yarrison ${ }^{25,26}$. Detailed explanation of the model used can be found in our previous publication ${ }^{26,44}$.

PC-SAFT parameters for pure water, based on the two electron donor and the two electron acceptor association scheme (also called the $4 \mathrm{C}$ association scheme), as well as for pure nonassociating $\mathrm{CH}_{4}, \mathrm{CO}_{2}, \mathrm{H}_{2} \mathrm{~S}, \mathrm{NO}_{2}, \mathrm{~N}_{2}$ and Ar components are illustrated in Table 1.

Interactions in both $\mathrm{CO}_{2}$-water and $\mathrm{H}_{2} \mathrm{~S}$-water systems have been extensively studied experimentally and theoretically through $a b$ initio calculations. Results indicated that the interactions between acid gases and water molecules are dominantly of a Lewis acid-base nature along with weaker hydrogen bonding interactions. Danten et al. ${ }^{54}$ claim that the carbon atom in carbon dioxide acts as an electron acceptor while oxygen atom in water acts as an electron donor. On the other hand, quantum calculations ${ }^{55-57}$ performed by different researchers suggest that the most stable interaction existing between water and hydrogen sulfide occurs when the latter acts as an electron donor while water acts as an electron acceptor.

Following the approach taken previously by Tsivintzelis et al. ${ }^{34,35}$ in modeling water content of acid gases using the cubic plus association (CPA) equation of state, cross association between $\mathrm{H}_{2} \mathrm{~S}$-water and $\mathrm{CO}_{2}$-water were taken into consideration, in this work, through modeling $\mathrm{H}_{2} \mathrm{~S}$ 
with two negative association sites and $\mathrm{CO}_{2}$ with two positive association sites. Self-association between $\mathrm{H}_{2} \mathrm{~S}$ molecules are known to be weak, and hence neglected. In order to reduce the number of fitting parameters, cross association energies $\left(\varepsilon^{A_{i} B_{j}} / k\right)$ were fixed to values determined through calorimetric ${ }^{37}$ and infrared (IR) spectroscopic ${ }^{38}$ experiments. The work by Tsivintzelis et al. ${ }^{34,35}$ required large binary interaction parameters $\left(k_{i j}\right)$ between $\mathrm{CO}_{2}, \mathrm{H}_{2} \mathrm{~S}$ and water as a second fitting parameter. On the other hand, all $k_{i j}$ values were set to zero throughout this work. As a result, the only remaining parameter to be fit to experimental data is the cross association volume $\left(\kappa^{A_{i} B_{j}}\right)$. Assuming $\kappa^{A_{i} B_{j}}$ to be temperature independent, corresponding parameters for $\mathrm{CO}_{2}$-water and $\mathrm{H}_{2} \mathrm{~S}$-water were fitted to single temperature water content data at $304.21 \mathrm{~K}\left(87.9^{\circ} \mathrm{F}\right)$ and $366.48 \mathrm{~K}\left(200{ }^{\circ} \mathrm{F}\right)$ respectively. In this way the model predictive power in calculating water mole fractions at different conditions can be better examined. Table 2 illustrates the cross association parameters used in this work.

\section{Results and Discussion}

\section{Measured water content of $\mathrm{CO}_{2}$ containing natural gas mixtures}

Water content of $\mathrm{CO}_{2}$ containing natural gas mixtures are reported in Table 3 based on the approach described in the experimental setup section.

\section{Water content of pure carbon dioxide}

Vapor-liquid equilibrium (VLE) of water-carbon dioxide system was modeled using Eqs. 1-3. Experimental data by Gillespie and Wilson as well as Song and Kobayashi on the solubility of water in carbon dioxide at $304.21 \mathrm{~K}\left(87.9^{\circ} \mathrm{F}\right)$ was used to fit the cross association volume $\left(\kappa^{A_{i} B_{j}}\right)$ parameter as shown in Table 2. An average absolute deviation (AAD) of $7.82 \%$ was 
calculated from the optimization algorithm. Figure 3 (a)-(f) exhibits results obtained at different temperatures while setting the binary interaction parameter as zero.

The model predictions appear to be in good agreement with the existing experimental data up to high temperatures and pressures. In reference to Figure 3 (a)-(d), it can be observed that water content tends to decrease up to intermediate pressures followed by a sudden jump in water mole fraction caused by $\mathrm{CO}_{2}$ phase transition from vapor to liquid. This phenomena can no longer be observed above pure $\mathrm{CO}_{2}$ critical point as shown in Figure 3 (e)-(f). In general, the solubility of water in $\mathrm{CO}_{2}$ vapor phase can be captured using an inert $\mathrm{CO}_{2}$ scheme as proposed by Gross and Sadowski $^{41}$. However, once the mixture dew point pressure is reached, hydrogen bonding becomes more significant with the density increase. As a result, the sudden increase in water content can only be captured through considering cross association between $\mathrm{CO}_{2}$ and water. The theory confirms experimental observations suggesting a weak dependence on pressure for water mole fraction in the liquid $\mathrm{CO}_{2}$ phase.

\section{Water content of pure hydrogen sulfide}

Experimental data on water content of hydrogen sulfide is limited. Among these data points found in the literature, are smoothed values published by Selleck et al. ${ }^{10}$ based on the scattered experimental data measured by Gillespie et al. ${ }^{11}$ The model cross association volume, $\kappa^{A_{i} B_{j}}$, was fitted to experimental data by Gillespie et al. ${ }^{11}$ at a temperature of $366.48 \mathrm{~K}\left(200{ }^{\circ} \mathrm{F}\right)$. An average absolute deviation (AAD) of $13.8 \%$ was calculated from the optimization algorithm. The fitted value was then used to predict water solubility at different temperatures as shown in Figure 4 (a)(e). 
In reference to Figure 4 (b), the model over predicts water solubility in liquid $\mathrm{H}_{2} \mathrm{~S}$ phase at $344.26 \mathrm{~K}\left(160{ }^{\circ} \mathrm{F}\right)$ in comparison to the experimental values by Gillespie et al. ${ }^{11}$ The same trend was obtained by Carroll ${ }^{17,22}$ using AQUAlibrium software package which uses a Peng-Robinson (PR) equation of state in modeling the non-aqueous phase. Moreover, another set of smoothed data from Selleck et al. ${ }^{10}$ does not show a three phase point at temperature of $377.59 \mathrm{~K}\left(220{ }^{\circ} \mathrm{F}\right)$, which is above pure $\mathrm{H}_{2} \mathrm{~S}$ critical point. However, the model in Figure 4 (d) predicts the existence of a three phase point which is in agreement with what has been shown previously by Carroll and Mather $^{61}$. In general, the agreement between the model predictions and literature values is reasonable considering the scatter found in the original experimental data.

\section{Water content of pure nitrogen, argon and nitrous oxide}

Modeling phase behavior of water-nitrogen and water-argon binary systems is simpler than that of $\mathrm{CO}_{2}, \mathrm{H}_{2} \mathrm{~S}$ and $\mathrm{N}_{2} \mathrm{O}$ since no LLE is formed at conditions under consideration. Coan and $\mathrm{King}^{58}$ argue that $\mathrm{N}_{2} \mathrm{O}$ hydration occurs in the vapor phase as a result of Lewis acid-base type of interactions. Since, no LLE data is found in the literature for $\mathrm{N}_{2} \mathrm{O}$-water system and hydration is expected to be weak in the vapor phase, cross association between $\mathrm{N}_{2} \mathrm{O}$ and water was neglected in this work. Moreover, parameters for $\mathrm{N}_{2} \mathrm{O}$ were obtained through fitting pure saturated liquid densities and vapor pressures as shown in Figure 5 (a)-(b) and Table 1.

Experimental data ${ }^{48,63-70}$ found in the literature for nitrogen systems cover a wide range of conditions from $273-623 \mathrm{~K}\left(32-662{ }^{\circ} \mathrm{F}\right)$ and up to $135 \mathrm{MPa}(19,580 \mathrm{psia})$. On the other hand, the only data available on water content of compressed $\operatorname{argon}^{48}$ and nitrous oxide ${ }^{58}$ cover a narrower range of temperature from $298.15-373.15 \mathrm{~K}\left(77-212^{\circ} \mathrm{F}\right)$ and pressures up to $9.27 \mathrm{MPa}(1345$ psia) and 5.00 $\mathrm{MPa}(725 \mathrm{psia})$ respectively. Again, the $k_{i j}$ parameters were set to zero as 
followed in the case of water-alkane and water- $\mathrm{CO}_{2} / \mathrm{H}_{2} \mathrm{~S}$ systems. As evident in Figures 6-8, there is good agreement between the model predictions and the experimental data.

\section{Water content in methane- $\mathrm{CO}_{2}$ and methane- $\mathrm{H}_{2} \mathrm{~S}$ mixtures}

Natural gas streams entering a glycol dehydration unit in a gas plant is usually a mixture of light hydrocarbons, mostly composed of methane, water, small percentages of carbon dioxide and traces of hydrogen sulfide. Therefore, modeling the effect of acid gases on water content of methane is essential for industrial applications. To do so, binary mixtures of methane-carbon dioxide and methane-hydrogen sulfide needs to be first modeled using PC-SAFT. Figure 9 (a)(b) depicts the phase behavior of methane-carbon dioxide and methane-hydrogen sulfide respectively.

Fitted binary interaction parameters along with the absolute average deviations from experiment are shown in Table 4 for methane-carbon dioxide and methane-hydrogen sulfide systems. The binary interaction parameter tabulated for carbon dioxide-hydrogen sulfide system will be used later in the next section of this work. Although adding a $k_{i j}$ value to each of these systems has been proved to substantially reduce the error in the liquid phase, we decided to keep the model predictive and neglect them while modeling the ternary systems. Figure 10 (a)-(f) demonstrates the effect of adding $\mathrm{CO}_{2}$ at different concentrations on the solubility of water in the methane-rich phase.

The agreement between the model predictions and the experimental values for Figure 10 (a)-(e) is satisfactory. Now, the model was used to predict water content at conditions where experimental data is absent. Figure 10 (f) shows water solubility in methane-carbon dioxide mixture as a function of pressure and composition at $298.15 \mathrm{~K}\left(77^{\circ} \mathrm{F}\right)$. An increase in the 
pressure from 1.38 to $5.52 \mathrm{MPa}(200-800$ psia) leads to a reduction in the solubility of water in the vapor phase. At a constant pressure, it is demonstrated that water content decreases linearly with increasing methane concentration. However, a pressure point is reached where liquid $\mathrm{CO}_{2}$ starts forming and a jump in water content of pure $\mathrm{CO}_{2}$ occurs. PC-SAFT calculated that dew point pressure, at $298 \mathrm{~K}\left(77^{\circ} \mathrm{F}\right)$, to be about $6.24 \mathrm{MPa}$ (905 psia). The sudden decrease in water content at $6.55 \mathrm{MPa}(950 \mathrm{psia})$ is due to the phase transition from liquid to vapor once methane is added to the system. Further increase in pressure from 13.79-20.68 MPa (2000-3000 psia) resulted in an increase in the water content of the supercritical natural gas fluid. However, now water mole fraction decreases exponentially with increasing methane concentration at a constant pressure. Figure 11 (a)-(b) depicts the solubility of water in two different gas mixtures of methane-hydrogen sulfide at $327.59 \mathrm{~K}\left(130^{\circ} \mathrm{F}\right)$.

As expected, the effect of $\mathrm{H}_{2} \mathrm{~S}$ composition the on water content of the methane-rich vapor phase was weak. Tables 5 and 6 compare the model performance against predictions done by Carroll ${ }^{21}$ using McKetta-Wehe chart, Wichert correction, AQUAlibrium software package (AQUA.) and Bukacek-Maddox method (B-M).

Although the binary interaction parameters for PC-SAFT have been set to zero, results show that PC-SAFT performs as well as Bukacek-Maddox method in predicting water content of $\mathrm{H}_{2} \mathrm{~S}$ systems and performs similar to AQUAlibrium software package in predicting water content of $\mathrm{CO}_{2}$ systems. Better predictions for the water content of $\mathrm{H}_{2} \mathrm{~S}$ can be achieved using McKettaWehe chart, Wichert correction and AQUAlibrium software package. Predictions for $\mathrm{H}_{2} \mathrm{~S}$ systems using PC-SAFT might be improved by tuning the $\kappa^{A_{i} B_{j}}$.

\section{Water content of sour natural gas mixtures}


Application of the water model in modeling a typical sour natural gas mixture is important for industrial processes. Accurate determination of water content is essential for preventing hydrate formation in pipelines. Also, designing injection schemes for EOR applications require a strong understanding of the phase behavior of wet acid gas systems. PC-SAFT predictive power was examined through modeling a quaternary mixture of methane, carbon dioxide, hydrogen sulfide and water at industrial pipeline conditions. First, the ability of the equation of state in describing $\mathrm{CO}_{2}-\mathrm{H}_{2} \mathrm{~S}$ binary system phase behavior was tested. In reference to Figure 12, it is interesting to observe as how adding a $k_{i j}$ value causes a change in the shape of the binary mixture phase envelope. The fitted $k_{i j}$ is listed in Table 4 .

Second, an attempt was made to predict water content of mixed $\mathrm{CO}_{2}-\mathrm{H}_{2} \mathrm{~S}$ gas mixture. Setting all $k_{i j}$ values as zero, PC-SAFT was able to adequately predict water content of the mixture at two different compositions as shown in Figure 13 (a)-(b). Now the model can be used confidently to model the quaternary mixture at industrial conditions.

Finally, water content of two quaternary mixtures was predicted and is shown in Table 7.

Generally, the error increases with increase in system temperature and pressure. The same observation can also be seen in Figure 3 (f) at a high temperature of $477.59 \mathrm{~K}\left(400{ }^{\circ} \mathrm{F}\right)$. It is worth noting that Clark $^{8}$ attempted to model Huang et al. ${ }^{75}$ data using AQUAlibrium software package and performed almost equal to PC-SAFT. Although, the absolute deviations (AD) are within $\pm 30 \%$ of the experimental data, setting $k_{i j}$ values as zero might have contributed in increasing the absolute average deviations. 


\section{Conclusion}

Water content of three $\mathrm{CO}_{2}$ containing natural gas mixtures was measured up to high temperatures and pressures and as a function of carbon dioxide concentration using a dynamic saturation method. A water model developed based on water content data in n-alkanes was used to predict water content of pure acid, inert and noble gases as well as acid gas mixtures containing methane. To do so, cross association between water- $\mathrm{CO}_{2}$ and water- $\mathrm{H}_{2} \mathrm{~S}$ was taken into account. Association energies were fixed to experimentally determined values, while association volumes were fitted to VLE and LLE data. Interaction parameters were set to zero throughout the work. The agreement between the model predictions and experimental data for pure acid, inert and noble gases was good up to high temperatures and pressures. Moreover, the effect of acid gas composition on water content of the methane rich phase was examined. Water mole fraction showed a weak dependence on acid gas composition at VLE conditions while a strong dependence was shown at supercritical conditions. Finally, an attempt was made to predict water content of a typical natural gas stream at industrial conditions. Errors were relatively high but were still within $\pm 30 \%$ of the experimental data. SAFT is a general model applicable to a wide range of systems; yet the results are competitive with the best models created for the specific case of water content in acid gas systems.

\section{Acknowledgment}

WAF gratefully acknowledges the Abu Dhabi National Oil Company (ADNOC) for financial support through a PhD scholarship. We gratefully acknowledge the financial support of the Gas Processors Association (GPA) and the Robert A. Welch Foundation (Grant No. C-1241). 


\section{Literature Cited}

1. Kohl AL, Nielson R. Gas purification: Houston: Gulf Publishing Company; 1997.

2. Kidnay AJ, Parrish WR. Fundamentals of natural gas processing. Vol 200: CRC Press; 2006.

3. Wiebe R, Gaddy V. The solubility in water of carbon dioxide at 50, 75 and 100, at pressures to 700 atmospheres. Journal of the American Chemical Society. 1939;61(2):315-318.

4. Wiebe R, Gaddy V. The solubility of carbon dioxide in water at various temperatures from 12 to 40 and at pressures to 500 atmospheres. critical phenomena*. Journal of the American Chemical Society. 1940;62(4):815-817.

5. Wiebe R, Gaddy V. Vapor phase composition of carbon dioxide-water mixtures at various temperatures and at pressures to 700 atmospheres. Journal of the American Chemical Society. 1941;63(2):475-477.

6. Gillespie PC, Wilson GM, Association GP. Vapor-liquid and liquid-liquid equilibria: water-methane, water-carbon dioxide, water-hydrogen sulfide, water-npentane, watermethane-npentane: Gas Processors Association; 1982.

7. Song KY, Kobayashi R. Water content of $\mathrm{CO} 2$ in equilibrium with liquid water and/or hydrates. SPE Formation Evaluation. 1987;2(04):500-508.

8. Clark MA. Experimentally obtained saturated water content, phase behavior and density of acid gas mixtures: University of Calgary; 1999.

9. Song KY, Kobayashi R. The water content of a carbon dioxide-rich gas mixture containing 5.31 Mol\% methane along the three-phase and supercritical conditions. Journal of Chemical and Engineering Data. 1990;35(3):320-322. 
10. Selleck F, Carmichael L, Sage B. Phase behavior in the hydrogen sulfide-water system. Industrial \& Engineering Chemistry. 1952;44(9):2219-2226.

11. Gillespie P, Owens J, Wilson G. Sour water equilibria extended to high temperatures and with inerts present. Paper presented at: AIChE Winter National Meeting, Atlanta, GA1984.

12. Chapoy A, Mohammadi AH, Tohidi B, Valtz A, Richon D. Experimental measurement and phase behavior modeling of hydrogen sulfide-water binary system. Industrial \& engineering chemistry research. 2005;44(19):7567-7574.

13. Sharma SC. Equilibrium water content of gaseous mixtures, The University of Oklahoma.; 1969.

14. Sharma S, Campbell J. Predict natural-gas water content with total gas usage. Oil \& Gas J. 1969;4:136-137.

15. Maddox RN. Gas and Liquid Sweetening: M. Campbell; 1974.

16. Maddox R, Lilly L, Moshfeghian M, Elizondo E. Estimating water content of sour natural gas mixtures. Paper presented at: Laurance Reid Gas Conditioning Conference1988.

17. Carroll JJ. The water content of acid gas and sour gas from 100 to $220^{\circ} \mathrm{F}$ and pressures to 10000 psia. Part 1 - Pure Components. Paper presented at: 81st Annual GPA Convention2002; Dallas, Texas, USA.

18. McCain WD. The properties of petroleum fluids: PennWell Books; 1990.

19. GPSA Engineering Data Book. 11 ed. Tulsa, OK: Gas Processors Suppliers Association; 1998. 
20. Wichert GC, Wichert E. Chart estimates water content of sour natural gas. Oil and Gas Journal;(United States). 1993;91(13).

21. Carroll JJ. The water content of acid gas and sour gas from 100 to $220^{\circ} \mathrm{F}$ and pressures to 10000 psia. Part 2 - Mixtures. Paper presented at: 81st Annual GPA Convention2002; Dallas, Texas, USA.

22. Carroll J. Phase equilibria relevant to acid gas injection: Part 2-Aqueous phase behaviour. Journal of Canadian Petroleum Technology. 2002;41(7):39-43.

23. Peng D-Y, Robinson DB. A new two-constant equation of state. Industrial \& Engineering Chemistry Fundamentals. 1976;15(1):59-64.

24. Saul A, Wagner W. International Equations for the Saturation Properties of Ordinary Water Substance. J. Phys. Chem. Ref. Data 1987;16(4):893-901.

25. Yarrison M. Measurement and modeling of the water content of high pressure sweet and acid natural gas systems [Dissertation], Rice University; 2007.

26. Yarrison M, Cox KR, Chapman WG. Measurement and Modeling of the Solubility of Water in Supercritical Methane and Ethane from 310 to $477 \mathrm{~K}$ and Pressures from 3.4 to $110 \mathrm{MPa}$. Industrial \& engineering chemistry research. 2006;45(20):6770-6777.

27. Valtz A, Chapoy A, Coquelet C, Paricaud P, Richon D. Vapour-liquid equilibria in the carbon dioxide-water system, measurement and modelling from 278.2 to 318.2 K. Fluid phase equilibria. 2004;226:333-344.

28. Wong DSH, Sandler SI. A theoretically correct mixing rule for cubic equations of state. AIChE Journal. 1992;38(5):671-680.

29. Renon H, Prausnitz JM. Local compositions in thermodynamic excess functions for liquid mixtures. AIChE journal. 1968;14(1):135-144. 
30. Gil-Villegas A, Galindo A, Whitehead PJ, Mills SJ, Jackson G, Burgess AN. Statistical associating fluid theory for chain molecules with attractive potentials of variable range. The Journal of chemical physics. 1997;106(10):4168-4186.

31. Alejandro AGLAD, Jackson G-VG. The thermodynamics of mixtures and the corresponding mixing rules in the SAFT-VR approach for potentials of variable range. Molecular Physics. 1998;93(2):241-252.

32. Valderrama JO. A generalized Patel-Teja equation of state for polar and nonpolar fluids and their mixtures. Journal of chemical engineering of Japan. 1990;23(1):87-91.

33. Avlonitis D, Danesh A, Todd A. Prediction of VL and VLL equilibria of mixtures containing petroleum reservoir fluids and methanol with a cubic EoS. Fluid Phase Equilibria. 1994;94:181-216.

34. Tsivintzelis I, Kontogeorgis GM, Michelsen ML, Stenby EH. Modeling phase equilibria for acid gas mixtures using the CPA equation of state. I. Mixtures with H2S. AIChE journal. 2010;56(11):2965-2982.

35. Tsivintzelis I, Kontogeorgis GM, Michelsen ML, Stenby EH. Modeling phase equilibria for acid gas mixtures using the CPA equation of state. Part II: Binary mixtures with CO2. Fluid Phase Equilibria. 2011;306(1):38-56.

36. Kontogeorgis GM, Voutsas EC, Yakoumis IV, Tassios DP. An equation of state for associating fluids. Industrial \& engineering chemistry research. 1996;35(11):4310-4318.

37. Wormald CJ, Colling, C.N., Sellars, A.J. Thermodynamic properties of gaseous mixtures containing water. International Gas Research Conference: Government Inst Inc, Rockville, Md, USA; 1983:1070-1079. 
38. Sennikov P, Shkrunin V, Tokhadze K. Intermolecular interactions of hydrogen sulphide and hydrogen selenide with some proton donors and proton acceptors in liquid phase. Journal of Molecular Liquids. 1990;46:29-38.

39. Chapman WG, Jackson G, Gubbins KE. Phase equilibria of associating fluids: chain molecules with multiple bonding sites. Molecular Physics. 1988;65(5):1057-1079.

40. Chapman WG, Gubbins KE, Jackson G, Radosz M. New reference equation of state for associating liquids. Industrial \& Engineering Chemistry Research. 1990;29(8):17091721.

41. Gross J, Sadowski G. Perturbed-chain SAFT: An equation of state based on a perturbation theory for chain molecules. Industrial \& engineering chemistry research. 2001;40(4):1244-1260.

42. Gross J, Sadowski G. Application of the perturbed-chain SAFT equation of state to associating systems. Industrial \& engineering chemistry research. 2002;41(22):55105515.

43. Emborsky CP, Cox KR, Chapman WG. Correlation and Prediction of Water Content in Alkanes Using a Molecular Theory. Industrial \& Engineering Chemistry Research. 2011;50(13):7791-7799.

44. Fouad WA, Ballal D, Cox KR, Chapman WG. Examining the Consistency of Water Content Data in Alkanes Using the Perturbed-Chain Form of the Statistical Associating Fluid Theory Equation of State. Journal of Chemical \& Engineering Data. 2013;59(4):1016-1023. 
45. Wagner W, Pruß A. The IAPWS formulation 1995 for the thermodynamic properties of ordinary water substance for general and scientific use. Journal of Physical and Chemical Reference Data. 2002;31:387.

46. Errington JR, Boulougouris GC, Economou IG, Panagiotopoulos AZ, Theodorou DN. Molecular simulation of phase equilibria for water-methane and water-ethane mixtures. The Journal of Physical Chemistry B. 1998;102(44):8865-8873.

47. Prausnitz J, Benson P. Solubility of liquids in compressed hydrogen, nitrogen, and carbon dioxide. AIChE Journal. 1959;5(2):161-164.

48. Rigby M, Prausnitz JM. Solubility of water in compressed nitrogen, argon, and methane. The Journal of Physical Chemistry. 1968;72(1):330-334.

49. Krichevsky I, Kasarnovsky J. Thermodynamical calculations of solubilities of nitrogen and hydrogen in water at high pressures. Journal of the American Chemical Society. 1935;57(11):2168-2171.

50. Harvey AH. Semiempirical correlation for Henry's constants over large temperature ranges. AIChE journal. 1996;42(5):1491-1494.

51. Versteeg GF, Van Swaalj W. Solubility and diffusivity of acid gases (carbon dioxide, nitrous oxide) in aqueous alkanolamine solutions. Journal of Chemical and Engineering Data. 1988;33(1):29-34.

52. Lyckman E, Eckert C, Prausnitz J. Generalized reference fugacities for phase equilibrium thermodynamics. Chemical Engineering Science. 1965;20(7):685-691.

53. Nasrifar K, Tafazzol AH. Vapor- Liquid Equilibria of Acid Gas- Aqueous Ethanolamine Solutions Using the PC-SAFT Equation of State. Industrial \& Engineering Chemistry Research. 2010;49(16):7620-7630. 
54. Danten Y, Tassaing T, Besnard M. Ab initio investigation of vibrational spectra of water(CO2) $n$ complexes $(n=1,2)$. The Journal of Physical Chemistry A. 2005;109(14):32503256.

55. Del Bene JE. Ab initio molecular orbital study of the structures and energies of neutral and charged bimolecular complexes of water with the hydrides $\mathrm{AHn}(\mathrm{A}=$ nitrogen, oxygen, fluorine, phosphorus, sulfur, and chlorine). The Journal of Physical Chemistry. 1988;92(10):2874-2880.

56. Novaro O, Leś A, Galván M, del Conde G. Theoretical study of three-body nonadditive interactions for the H2S-(H2O)2 system. Theoretica chimica acta. 1983;64(2):65-81.

57. Leś A. A pseudopotential study of the hydrogen bond in $\mathrm{H} 2 \mathrm{O} \cdot \mathrm{H} 2 \mathrm{~S}, \mathrm{H} 2 \mathrm{~S} \cdot \mathrm{H} 2 \mathrm{~S}$ and $\mathrm{H} 2 \mathrm{O}$. H2Se systems. Theoretica chimica acta. 1985;66(6):375-393.

58. King Jr AD, Coan C. Solubility of water in compressed carbon dioxide, nitrous oxide, and ethane. Evidence for hydration of carbon dioxide and nitrous oxide in the gas phase. Journal of the American Chemical Society. 1971;93(8):1857-1862.

59. Nakayama T, Sagara H, Arai K, Saito S. High pressure liquid $\square$ liquid equilibria for the system of water, ethanol and 1, 1-difluoroethane at 323.2 K. Fluid Phase Equilibria. 1987;38(1):109-127.

60. Burgess MP, Germann RP. Physical properties of hydrogen sulfide-water mixtures. AIChE Journal. 1969;15(2):272-275.

61. Carroll JJ, Mather AE. Phase equilibrium in the system water-hydrogen sulphide: Modelling the phase behavior with an equation of state. The Canadian Journal of Chemical Engineering. 1989;67(6):999-1003. 
62. Lemmon E, McLinden M, Friend D. Thermophysical Properties of Fluid Systems in NIST Chemistry WebBook, NIST Standard Reference Database Number 69, Eds. Linstrom, PJ and Mallard, WG, National Institute of Standards and Technology, Gaithersburg MD, 208992011.

63. Mohammadi AH, Chapoy A, Tohidi B, Richon D. Water content measurement and modeling in the nitrogen+ water system. Journal of Chemical \& Engineering Data. 2005;50(2):541-545.

64. Tabasinejad F, Moore RG, Mehta SA, et al. Water Solubility in Supercritical Methane, Nitrogen, and Carbon Dioxide: Measurement and Modeling from 422 to $483 \mathrm{~K}$ and Pressures from 3.6 to $134 \mathrm{MPa}$. Industrial \& Engineering Chemistry Research. 2011;50(7):4029-4041.

65. Althaus K. Fortschritt-Berichte VDI; 1999. Reihe 3: 350 (in German). Oellrich LR; Althaus K. GERG-Water Correlation (GERG Technical Monograph TM14) Relationship Between Water Content and Water Dew Point Keeping in Consideration the Gas Composition in the Field of Natural Gas. Fortschritt-Berichte VDI 2000: Reihe.

66. Kosyakov N, Ivchenko B, Krishtopa P. Solubility of moisture in compressed gases at low temperatures. Vopr. Khim. Khim. Tekhnol. 1982;68:33-36.

67. Gillespie P, Wilson G. Vapor-Liquid Equilibrium Data on Water-Substitute Gas Components: N2-H2O, H2-H2O, CO-H2O: H2-CO-H2O and H2S-H2O, 41, Gas Processors Association, Gas Processors Association Research Report, Provo, UT;1980.

68. Kosyakov N, Ivchenko B, Krishtopa P. Moisture contents of compressed nitrogen and hydrogen at low-temperatures. Vol 50: Plenum Publ Corp Consultants Bureau, 233 Spring St, New York, NY 10013; 1977:2436-2438. 
69. Bukacek RF. Equilibrium moisture content of natural gases: Institute of Gas Technology; 1955.

70. Bartlett EP. The concentration of water vapor in compressed hydrogen, nitrogen and a mixture of these gases in the presence of condensed water. Journal of the American Chemical Society. 1927;49(1):65-78.

71. Davalos J, Anderson WR, Phelps RE, Kidnay AJ. Liquid-vapor equilibria at 250.00. deg. $\mathrm{K}$ for systems containing methane, ethane, and carbon dioxide. Journal of Chemical and Engineering Data. 1976;21(1):81-84.

72. Reamer H, Sage B, Lacey W. Phase Equilibria in Hydrocarbon Systems-Volumetric and Phase Behavior of the Methane-Hydrogen Sulfide System. Industrial \& Engineering Chemistry. 1951;43(4):976-981.

73. Chapoy A, Coquelet C, Liu H, Valtz A, Tohidi B. Vapour-liquid equilibrium data for the hydrogen sulphide $(\mathrm{H} 2 \mathrm{~S})+$ carbon dioxide $(\mathrm{CO} 2)$ system at temperatures from 258 to 313K. Fluid Phase Equilibria. 2013;356:223-228.

74. Lukacs J, Robinson D. Water content of sour hydrocarbon systems. Old SPE Journal. 1963;3(4):293-297.

75. Huang SS-S, Leu A-D, Ng H-J, Robinson DB. The phase behavior of two mixtures of methane, carbon dioxide, hydrogen sulfide, and water. Fluid Phase Equilibria. 1985;19(1):21-32. 